\title{
Psychological Distress among Caregivers of Children with Neurodevelopmental Disorders in Nepal
}

\author{
Hans Kristian Maridal ${ }^{1,2, * \mathbb{D}}$, Hanne Marit Bjørgaas ${ }^{3}$, Kristen Hagen ${ }^{1,4}{ }^{\mathbb{D}}$, Egil Jonsbu ${ }^{1,4}$, Pashupati Mahat ${ }^{5}$, \\ Shankar Malakar ${ }^{5}$ and Signe Dørheim ${ }^{6}$
}

1 Department of Psychiatry, Molde Hospital, Møre and Romsdal Hospital Trust, 6412 Molde, Norway; kristen.hagen@helse-mr.no (K.H.); egil.jonsbu@helse-mr.no (E.J.)

2 Department of Research, Division of Psychiatry, Haukeland University Hospital, Health Bergen, 5021 Bergen, Norway

3 Department of Pediatric Neurology/Habilitation, Habu, Stavanger University Hospital, 4068 Stavanger, Norway; hanne.marit.bjorgaas@sus.no

4 Department of Mental Health, Faculty of Medicine and Health Science, NTNU, 7491 Trondheim, Norway

5 Centre for Mental Health and Counseling Nepal, Thapathali, Jeetjung Marg, Kathmandu 44600, Nepal; drpashupati@mos.com.np (P.M.); shankar.malakar@gmail.com (S.M.)

6 Sandnes District Psychiatric Centre, Division of Psychiatry, Stavanger University Hospital, 4068 Stavanger, Norway; signe.karen.dorheim@sus.no

* Correspondence: Hans.Kristian.Maridal@helse-mr.no

check for

updates

Citation: Maridal, H.K.; Bjørgaas, H.M.; Hagen, K.; Jonsbu, E.; Mahat, P.; Malakar, S.; Dørheim, S.

Psychological Distress among

Caregivers of Children with

Neurodevelopmental Disorders in

Nepal. Int. J. Environ. Res. Public

Health 2021, 18, 2460. https://doi.

org/10.3390/ijerph18052460

Academic Editor: Paul B. Tchounwou

Received: 11 January 2021

Accepted: 23 February 2021

Published: 2 March 2021

Publisher's Note: MDPI stays neutral with regard to jurisdictional claims in published maps and institutional affiliations.

Copyright: (C) 2021 by the authors Licensee MDPI, Basel, Switzerland. This article is an open access article distributed under the terms and conditions of the Creative Commons Attribution (CC BY) license (https:/ / creativecommons.org/licenses/by/ $4.0 /)$.
Abstract: Parenting a child with neurodevelopmental disorder (NDD) is related to a higher rate of anxiety and depression, increased stress, and reduced quality of life. Although there is reason to believe that parenting children with NDD in low- and middle-income countries (LMIC) can be challenging, there is a lack of knowledge on the psychological distress among these caregivers, especially in rural areas. The aim of the study was to examine the psychological distress among caregivers having children with NDD in rural Nepal. Sixty-three caregivers were visited in their homes and interviewed by experienced mental health professionals. This study examined demographic information, severity of disability, perceived caregiver burden, and psychological distress, measured by the General Health Questionnaire-12 (GHQ-12). The study found a high level of psychological distress in the caregivers $(M=5.38, S D=2.8)$. A majority $(90.5 \%)$ scored two or higher, indicating the presence of a common mental disorder (CMD). Almost half $(46 \%)$ scored six or higher, indicating a high level of distress. A majority of the caregivers reported that caring for their disabled child had a negative effect on the caregiver's economy (70\%), physical health $(65 \%)$, social life $(64 \%)$, and dreams and expectations for the future (81\%). There was a significant relationship between the caregiver's psychological distress (GHQ-12) and degree of disability in the child (Gross Motor Function Classification System), degree of caregiver burden, feeding problems, having health workers as a possible source of help, receiving incentive from the government, having somebody to confide in, and caregiver illiteracy. A forward regression analysis entering the significant factors indicated that caregiver burden, having someone to confide in, and having health workers as a possible source of help were significant related to psychological distress. The final step of the model explained $42.4 \%$ of the variance in psychological distress among the caregivers. The study indicates a high level of psychological distress and high overall burden in caregivers of children with NDD in rural Nepal. Further implications for research and service development are discussed.

Keywords: neurodevelopmental disorder; disability; caregiver; psychological distress; low-income country; depression; anxiety; burden; Nepal

\section{Background}

Parenting a child with neurodevelopmental disorder (NDD) can be challenging [1,2]. In some parts of the world this challenge can be further exacerbated by poverty and lack 
of support from the surroundings [3]. NDD is a term used for a range of disorders that involve injuries to the developing brain, such as cerebral palsy and genetic disorders, and also intellectual disability and other conditions that lead to functional limitations such as impaired cognition, motor performance, vision, hearing, and speech, and behavior problems $[4,5]$. There is a lack of epidemiological data on NDD prevalence in low- and middle-income countries (LMIC) [6], but it is estimated that between 93 and 150 million children suffer from some kind of disability, and most of these live in low-income countries $[7,8]$. Children with disabilities are often not represented in official statistics and as a result remain politically and socially "invisible" [9]. Overall, NDD conditions are likely to be more common in low- and middle-income countries (LMIC) because of the higher prevalence of recognized risk factors such as poor maternal and child healthcare in the prenatal and postnatal period, nutritional deficiencies, and neonatal infections [6].

NDD is a public health challenge for LMIC [10] on account of their high prevalence, lifetime duration, and considerable social, personal, and economic consequences, as well as the impact on educational and employment opportunities in later life. Treatment, prevention, and management of these conditions are often not considered in healthcare plans, although they place a heavy burden on healthcare systems [11].

There is a growing understanding of the impact of NDD on the quality of life and mental health of families with children with these conditions. However, the majority of research has been conducted in high-income countries, and there is a lack of knowledge on the situation in low- and middle-income countries [12]. Research from high-income countries has shown substantially increased stress [1,2,13,14], chronicity of distress [15], fatigue [2], higher rate of anxiety and depression [12,16], emotional and cognitive problems [17], and a greater likelihood of having physical illness $[17,18]$ for these caregivers. They also forfeit employment opportunities, leisure time, and social interactions and often become housebound [2].

Moreover, there are also substantial economic challenges in having a child with a disability [19]. In LMIC with little or no governmental support, this is believed to be an even greater problem and can make caregivers impoverished and indebted [20].

Caregiving experiences in different contexts may also differ, as there are many additional challenges in raising a child with NDD in LMIC [3,21]. Social isolation and psychological distress can be further exacerbated by stigma, exclusion, and inequitable policies [2].

The presence of psychiatric distress in the caregiver is associated with reports of poorer social support, family dysfunction, greater adverse impact of the child's situation on the family, poorer child behavior, unfavorable parenting styles, poorer child psychosocial functioning [22], and even a negative impact on siblings and marriage [23]. Maternal depression has been shown to affect the child's psychological, intellectual, and psychosocial development, and may increase the risk of malnourishment and physical as well as psychiatric illness in the child [4]. The resources, family support, and overall functioning of the family are important factors for achieving a satisfying life for children with disabilities [24]. It is therefore important to gain more knowledge about the psychological distress of these parents in LMIC.

According to Thrush and Hyder, the lack of information, especially quantitative data, on the situation of caregivers and their burden in LMIC allows the perpetuation of the misleading notion that families in LMIC are capable of providing care without public or private institutional support [3], and better evidence would provide incentive for governments of LMIC to put the needs of caregivers higher on their agenda.

Some studies have shown that caregivers in low-income countries seem to have a higher risk of suffering from some form of psychiatric morbidity [25-29]. Disability in the child may have a large impact on the lives, economy, and mental health of caregivers in LMIC [20]. Young people with disabilities in LMIC are less likely to ever enroll school, have limited access to both education and health services, and are at increased risk of isolation, social exclusion, experiencing physical violence, and sexual and emotional abuse [30]. 
However, much of the research in LMIC settings seems to have been done on convenience samples, often in a major city or on caregivers attending a cerebral palsy $(\mathrm{CP})$ center or in others already receiving help.

Studies of caregivers of patients with mental disorders like schizophrenia and bipolar disorder in Nepal have shown a high level of stress-, depression-, and anxiety-related problems [31,32]. A study from a hospital in the city of Dhahran found that caretakers of intellectually disabled children in the hospital had a high level of anxiety and depression [33]. There seems to be a lack of knowledge of the caregiver situation especially in rural areas. To our knowledge, no studies on the psychological distress of NDD children's caregivers have been published from rural Nepal. We have chosen to focus on the situation in rural areas, where most of the population in Nepal lives and where children with disabilities often receive no or very limited help.

Nepal has a difficult geography and infrastructure, and accessibility to roads is limited in many parts of the country. Eighty percent of the population lives in rural areas, and $40 \%$ of women are illiterate. It is among the poorest countries in the world, with about a quarter of its population living below the poverty line [34]. Studies have shown that the prevalence of mental illness such as depression in Nepal is similar to the prevalence in the developed world $[35,36]$.

Cultural understanding, attitudes, and concepts of both mental health and disability differ and have an effect on stress, coping [37], and help-seeking behavior [38], and can thereby lead to ineffective treatment. Clarke and colleagues found that Nepali mothers concepts of psychological distress were often attributed to family- and gender-related factors. The distress often developed in a context of perceived duty towards the family and limited autonomy for women, and the response to distress was often shaped by a fatalistic worldview [39]. A report by Human Rights Watch found that families with disabilities are stigmatized and there is a strong belief in Nepal that disability is due to sins in a past life, fate, and God's will. They also found that these beliefs often prevent caregivers from accessing appropriate education or healthcare for their disabled child because of shame, stigma, and an inability to see the possible benefit [40].

Resources for both disability and mental healthcare in Nepal are very limited, and there is a major lack of trained manpower, service centers, and integration of mental health into primary healthcare [41-43].

\section{Aim of the Study}

The aim of this study was to estimate the psychological distress of caregivers with children suffering from NDD in rural Nepal and to find the factors associated with psychological distress.

\section{Methods and Material}

\subsection{Participants and Procedure}

Participants were 63 primary caregivers of children aged 2-12 years suffering from NDD in four districts of Nepal (Chitwan, Bardia, Baglung, and Sunsari), covering eastern, western, and middle parts of the country. The inclusion criteria were as follows: primary caregivers of children aged 2-12 years with NDD [44]. The primary caregiver was defined as the person responsible for the day-to-day decision-making and care of the child. If the primary caregiver was a sibling under 18 years old, the person who had custodial authority (overall responsibility for care and control) was selected (see Table 1 for details).

Inclusion in the study was decided by trained child habilitation workers from the SelfHelp Group for Cerebral Palsy (SGCP), an organization working with child habilitation in rural areas through a task-shifting approach. As there is no public register of children with NDD and these children were not enrolled for NDD treatment in the SGCP, information about possible children with NDD in the area was gathered from local people, youth clubs, local authorities, and other organizations. These children were then visited by a child 
habilitation worker, examined for possible NDD, and the caregiver invited to participate in the study. To our knowledge, none of the caregivers declined to participate in the study.

Table 1. Caregiver and child characteristics and relationship to the General Health Questionnaire-12 (GHQ-12).

\begin{tabular}{|c|c|c|c|c|c|c|}
\hline & Variable (Range/\%) & $\%$ & $\mathbf{M}(S D)$ & $r$ & $t$ & $p$ \\
\hline \multicolumn{7}{|c|}{ Caregiver characteristics } \\
\hline & Age in years (19-68) & & $31.51(8.53)$ & 0.056 & & 0.662 \\
\hline & Nuclear family & 50.8 & & & 1.269 & 0.209 \\
\hline & Illiteracy & 39.7 & & & 2.059 & 0.044 * \\
\hline & No schooling & 49.2 & & & 1.211 & 0.231 \\
\hline & No school leaving certificate & 90.5 & & & 0.353 & 0.725 \\
\hline & Not working outside home & 76.2 & & & 0.183 & 0.856 \\
\hline & Migrant worker partner & 28.1 & & & 0.259 & 0.797 \\
\hline \multirow[t]{8}{*}{ Help sources } & & & 2.29 (1.16) & -0.176 & & 0.166 \\
\hline & Help from partner & 82.5 & & & -0.216 & 0.830 \\
\hline & Help from grandparents & 42.9 & & & 1.084 & 0.283 \\
\hline & Siblings & 17.5 & & & -0.743 & 0.460 \\
\hline & Other family members & 30.2 & & & -1.639 & 0.106 \\
\hline & Health workers & 36.5 & & & -2.354 & $0.022 *$ \\
\hline & Help from others & 19 & & & -0.066 & 0.948 \\
\hline & Have somebody to confide in & 87.3 & & & -2.262 & 0.027 * \\
\hline \multicolumn{7}{|c|}{ Child characteristics } \\
\hline & Age in years (2-12) & & $6.66(2.73)$ & -0.039 & & 0.762 \\
\hline & Female ${ }^{a}$ & 41 & & & -1.128 & 0.264 \\
\hline & GMFCS score (1-5) & & $3.60(1.27)$ & 0.418 & & $0.001 *$ \\
\hline & Child's interaction score (5-15) & & $9.45(3.29)$ & -0.108 & & 0.408 \\
\hline & $\begin{array}{c}\text { Receiving incentive from } \\
\text { government }\end{array}$ & 46 & & & 3.019 & 0.004 * \\
\hline
\end{tabular}

Note: ${ }^{*}$ significant at $p<0.05 ; r=$ Pearson correlation coefficient, ${ }^{a}=$ female coded 1 and male 0 . GMFCS: Gross Motor Function Classification System.

Data were collected through a semistructured interview administered by experienced, Nepalese female mental health personnel (a mental health nurse and a clinical psychologist) with broad experience of working with rural mental health projects. The interview guide was developed closely together with local expertise from Self-Help Group for Cerebral Palsy (SGCP) and Center for Mental Health and Counseling (CMC), to ensure the validity and relevance of the questions both culturally and linguistically. The interview guide was translated to Nepali, and the translation was discussed and then blind-translated back to English.

The interviewers were trained in administering the questionnaire, and both the tools and the questionnaire were piloted on families with NDD in Kathmandu. All questions were read out loud and filled in by the interviewers, with clarification and explanation provided where necessary to ensure that the caregivers understood the questions. To secure the privacy and quality of the interviews, at least one of the team members entertained the child, other family members, and bystanders so the interviewer could be alone with the respondent.

\subsection{Measures}

\subsubsection{Demographics}

The caregivers reported their own age, their child's age, marriage status, family type, literacy, education level, work outside the home, and partner's working status.

\subsubsection{Diagnostic Assessment of NDD}

The children were assessed for NDD by trained personnel from the SGCP on the basis of information from the caregivers and clinical observation prior to inclusion. During the 
subsequent interview, the children were again observed by these personnel, together with the research team, and all were confirmed to have NDD.

Information on level of function and disability in the child was captured using the Ten Questions Screen [45], a disability screening tool especially developed for LMIC settings and previously used in Nepal [46].

For assessing the severity of motor disability, an adapted version of the Gross Motor Function Classification System (GMFCS) was used [47,48]. The GMFCS classifies the motor function of children from Level 1 to Level 5 with increasing severity. In addition, the caregiver was asked if the child was having difficulties with incontinence, feeding problems, or physical pain.

\subsubsection{Psychological Distress}

Level of caregiver's psychological distress was assessed using the Nepali version of the General Health Questionnaire-12 (GHQ-12) [49]. The GHQ-12 is a common assessment tool for mental well-being [50-53] and measures common mental health problems, including the domains of depression, anxiety, somatic symptoms, and social withdrawal. It has been found to be a sensitive instrument for detection of anxiety and depression in caregivers [54]. Patel and colleagues found the GHQ-12 to have the best balance of discriminating ability and internal consistency to identify cases of common mental disorders, but recommend using a higher cutoff $(\geq 6)$ in very resource-limited settings [55].

The GHQ-12 includes 12 items, each with a four-point Likert scale, and asks questions like "Have you recently felt you couldn't overcome your difficulties? (0) Not at all, (1) no more than usual, (2) rather more than usual, (3) much more than usual". We used the binary scoring method recommended by Goldberg (1988) where the first two alternatives are coded 0 and the last two are coded 1, giving a maximum score of 12 . As an indication of probable psychiatric "caseness", a sum score $\geq 2$ is recommended as a cutoff [56]. The Nepali validation of the GHQ-12 established a cutoff of $\geq 2$, giving the scale good psychometric propriety with a sensitivity of $85.6 \%$ and a specificity of $75 \%$, a positive predictive value of $87 \%$, and a negative predictive value of $84 \%$ [49]. Cronbach's alpha for the GHQ-12 in the present study was 0.787 .

\subsubsection{Assessment of Impact of the Disabled Child on Caregiver's Situation}

The impact of the disabled child on the caregiver and family was measured with seven questions regarding the impact of the disabled child on central aspects of the caregiver's life and situation, namely, household economy, caregiver's physical health, workload, social life, marital relationship, dreams and expectations for their future, and effects on other siblings. We asked questions like "How has your child's problems had an impact on your own physical health?" The questions were selected and formulated based on discussion with experienced health workers from Self-Help Group for Cerebral Palsy (SHGCP) and Center for Mental Health and Counseling (CMC). The answers were coded 0 (no negative impact), 1 (negative impact), or 2 (very negative impact). The scores on each of the seven items were summed, which gave a total score from 0 to 14 , where a higher score indicates a higher burden on the caregiver. Cronbach's Alpha for the caregiver impact score was 0.822 .

\subsubsection{Assessment of the Child's Interaction and Participation in the Local Society}

Information about the child's interaction and participation in society was obtained by five questions regarding the degree of social interaction compared to other children of the same age in the community, asking if the child had normal (coded 3), somewhat less (coded 2), or much less (coded 1) participation in the following settings: family, contact with people outside the family, school, children's activities in the community, and attendance at activities and events in the local community. The assessments were done by questions like "When you compare your child to other children of his/hers age how much interaction (contact) does your child have with other people outside the family?". These domains and formulations were selected on the basis of discussion with experienced local health 
workers from SHGCP and CMC. The scores on each of the five items were summed, which gave a total score of 5-15, where a low score indicates a low degree of interaction and participation in the local community. Cronbach's Alpha for the child's interaction and participation score was 0.829 .

\subsection{Administration and Ethical Approval}

Ethical approval was given by the Nepal Health Research Council and the Regional Committee for Medical and Health Research Ethics (REC West: 2012/2241) in Norway.

\subsection{Statistics}

Descriptive statistics (means, standard deviations, and percentages) were used to characterize the sample. To explore the relationship between child and caregiver characteristics and psychological distress (GHQ-12), we used Pearson's correlations for continuous variables and Student's $t$-test for dichotomous variables. In order to explore which of the factors explained the most variance of psychological distress, we also conducted a multiple forward linear regression, entering the GHQ-12 score as dependent variable and the significant factors from the correlational analysis as independent variables.

\section{Results}

\subsection{Caregiver and Child Characteristics}

A total of 63 primary caregivers were interviewed, all of them women: 60 (95\%) were biological mothers, two (3\%) were grandmothers, and one $(2 \%)$ had another relation to the child (aunt). The majority of the caregivers (98\%) were married. The age of the child ranged from 2 to 12 years $(M=6.66, S D=2.73)$. Forty-one percent of the children were female. A summary of child and caregiver characteristics is given in Table 1.

\subsection{The Child's Disability and Impact on the Caregiver}

The mean GMFCS score was 3.60 (SD =1.27). Most of the children had difficulties with weakness and stiffness (95.2\%), movement (88.9\%), unclear speech $(73.0 \%)$, and ability to learn to do things like other children at the same age $(73.8 \%)$. Sixty percent of the children were incontinent, and thirty-eight percent had difficulties with feeding. The answers to the Ten Questions Screen tool for disability are given in Table 2.

Table 2. Ten Questions Screen tool for disability and relationship to the GHQ-12.

\begin{tabular}{|c|c|c|c|}
\hline Child Experience Significant Problem with: & Yes $(\%)$ & $t / r$ & $p$ \\
\hline 1. Delays in motor development & 98.4 & -0.589 & 0.558 \\
\hline 2. Reduced vision & 12.7 & 0.130 & 0.897 \\
\hline 3. Reduced Hearing & 17.7 & 0.025 & 0.980 \\
\hline 4. Understanding simple commands & 13.1 & 0.761 & 0.450 \\
\hline 5. Weakness/stiffness & 95.2 & 0.672 & 0.504 \\
\hline Movement & 88.9 & 0.385 & 0.701 \\
\hline 6. Fits/epilepsy & 32.3 & 1.635 & 0.107 \\
\hline 7. Learning & 73.8 & 0.860 & 0.393 \\
\hline 8. Speaking at all & 50.8 & 1.55 & 0.125 \\
\hline 9.Unclear speech & 73.0 & 0.049 & 0.961 \\
\hline 10. Mental slowness & 90.5 & 0.821 & 0.415 \\
\hline Sum (Range $5-10 ; M=5.58 ; \mathrm{SD}=1.21$ ) & & $0.121^{\mathrm{a}}$ & 0.360 \\
\hline \multicolumn{4}{|l|}{ Other problems } \\
\hline Incontinence & 60.3 & 0.794 & 0.430 \\
\hline Feeding & 38.1 & 2.324 & 0.023 * \\
\hline Pain & 87.3 & 1.678 & 0.098 \\
\hline
\end{tabular}

Note: * significant at $p<0.05,{ }^{\text {a }}$ Pearson correlation coefficient. 


\subsection{Impact of Disabled Child on Caregiver Burden (Caregiver Impact Score)}

A majority of the caregivers experienced the child as having a negative or very negative impact on household economy $(69.8 \%)$, their own physical health $(65.1 \%)$, other siblings $(44.4 \%)$, their workload $(74.6 \%)$, their own social life $(63.5 \%)$, and their own dreams and expectations for the future (81.0\%); see Table 3 for details.

Table 3. Caregiver impact score.

\begin{tabular}{|c|c|c|c|c|c|c|}
\hline \multirow{2}{*}{$\begin{array}{l}\text { Negative Impact of Child's } \\
\text { Disability on: }\end{array}$} & \multicolumn{3}{|c|}{ Impact (\%) } & \multirow[b]{2}{*}{ Mean (SD) } & \multicolumn{2}{|c|}{ Relationship to GHQ-12 } \\
\hline & $\begin{array}{l}\text { No Negative } \\
\text { Impact }\end{array}$ & $\begin{array}{l}\text { Negative } \\
\text { Impact }\end{array}$ & $\begin{array}{l}\text { Very Negative } \\
\text { Impact }\end{array}$ & & $r$ & $p$ \\
\hline Household economy & 30.2 & 31.7 & 38.1 & $1.08(0.8)$ & 0.45 & $<0.001^{* *}$ \\
\hline Your physical health & 34.9 & 42.9 & 22.2 & $0.87(0.8)$ & 0.44 & $<0.001^{* *}$ \\
\hline Your workload & 25.4 & 34.9 & 39.7 & $1.14(0.8)$ & 0.48 & $<0.001 *$ \\
\hline Other siblings & 55.6 & 33.3 & 11.1 & $0.56(0.7)$ & 0.36 & $0.004 *$ \\
\hline Your social life & 36.5 & 34.9 & 28.6 & $0.92(0.8)$ & 0.30 & $0.016^{*}$ \\
\hline Your marital relationship & 87.3 & 4.8 & 7.9 & $0.21(0.6)$ & 0.28 & $0.028 *$ \\
\hline $\begin{array}{l}\text { Your own dreams and } \\
\text { expectations for the future }\end{array}$ & 19 & 49.3 & 31.7 & $1.13(0.7)$ & 0.49 & $<0.001^{* *}$ \\
\hline Sum score (range 0-14) & & & & $5.91(3.61)$ & 0.579 & $<0.001^{* *}$ \\
\hline
\end{tabular}

Note: * significant at $p<0.05 ;{ }^{* *}$ significant at $p<0.01 ; r=$ Pearson correlation coefficient.

\subsection{Psychological Distress}

Psychological distress among caregivers was measured using the GHQ-12. The mean GHQ-12 score was $5.38(S D=2.76$, range $=0-12)$. A majority of $90.5 \%$ scored above the suggested cutoff $(\geq 2)$ for screening for psychiatric cases in the community in Nepal [49], and $46 \%$ scored $\geq 6$. The GHQ-12 scores are shown in Table 4 .

Table 4. The GHQ-12 scores $(n=63)$.

\begin{tabular}{ccc}
\hline & \multicolumn{2}{c}{ Binary Scoring (0-0-1-1) } \\
\cline { 2 - 3 } GHQ-12 Questions & $\mathbf{0 ~ N o}$ & $\begin{array}{c}\text { Yes } \\
\mathbf{\%}\end{array}$ \\
\hline (1) Lost much sleep over worry? & $49.2 \%$ & $50.8 \%$ \\
(2) Felt constantly under strain? & $34.9 \%$ & $65.1 \%$ \\
(3) Not been able to concentrate? & $68.3 \%$ & $31.7 \%$ \\
(4) Not felt that you are playing a useful part in things? & $77.8 \%$ & $22.2 \%$ \\
(5) Not been able to face up to your problems? & $76.2 \%$ & $23.8 \%$ \\
(6) Not felt capable of making decisions about things? & $63.5 \%$ & $36.5 \%$ \\
(7) Felt you couldn't overcome your difficulties? & $42.9 \%$ & $57.1 \%$ \\
(8) Not been feeling reasonably happy, all things considered? & $36.5 \%$ & $63.5 \%$ \\
(9) Not been able to enjoy normal day-to-day activities? & $63.5 \%$ & $36.5 \%$ \\
(10) Been feeling unhappy or depressed? & $28.6 \%$ & $71.4 \%$ \\
(11) Been losing confidence in yourself? & $49.2 \%$ & $50.8 \%$ \\
(12) Been thinking of yourself as a worthless person? & $71.4 \%$ & $28.6 \%$ \\
\hline
\end{tabular}

There was no relationship between caregiver's age, family type, or occupation on the GHQ-12 score. Caregivers who were illiterate had higher psychological distress $(M=6.24$, $S D=3.15)$ compared with those who were literate $(M=4.82, S D=2.34): t(61)=-2.06$, $p=0.044$. None of the ten disability questions were related to scores on the GHQ-12, and neither was the gender or age of the child. There was a significant relationship between the GHQ-12 score and the degree of disability (GMFCS: $r=0.418, p<0.001$ ) and feeding problems $(M=6.38, S D=2.57)$ compared to those without feeding problems $(M=4.77$, $S D=2.72): t(61)=2.32, p=0.023$.

There was a significant relationship between all of the subscales on the child impact scale and the GHQ-12 score. Those who received help from health workers had significantly 
lower scores on the GHQ-12 $(M=4.43, S D=2.02)$ compared with those who did not receive help $(M=5.93, S D=2.99): t(59.29)=-2.35, p=0.022$. There was no significant relationship between any of the other help sources and the GHQ-12 score, including the total number of help sources. Those who had someone to confide in (87.3\%) had significantly lower scores on the GHQ-12 $(M=5.09, S D=2.54)$ compared with those who did not $(M=7.38$, $S D=3.50): t(61)=-2.262, p=0.027$ (See Table 1 for details).

There was no significant relationship between the level of the child's interaction with family or local community and the GHQ-12 score. The correlations between the GHQ-12, GMFCS, interaction, and impact scores are given in Table 5.

Table 5. Pearson correlations between GHQ-12, GMFCS, interaction, and impact scores.

\begin{tabular}{cccc}
\hline & GMFCS & Child Interaction & Child Impact \\
\hline GHQ-12 & $0.418^{* *}$ & -0.108 & $0.579^{* *}$ \\
GMFCS & & $-0.651^{* *}$ & $0.418^{*}$ \\
Interaction & & & -0.235 \\
\hline
\end{tabular}

Note: GMFCS = Gross Motor Function Classification System score; child interaction = child's interaction score child impact $=$ child's impact score. Correlation is significant at: ${ }^{*} p<0.05$ and ${ }^{* *} p<0.01$ (two-tailed).

A multiple regression analysis, entering the significant factors from the correlational analyses, found that perceived caregiver burden $(\beta=0.57, p<0.001)$, having a close friend to confide in $(\beta=-0.23, p=0.021)$, and having help from health workers $(\beta=-0.21$, $p=0.039$ ) were significantly associated with GHQ-12. In total, the model explained $42.4 \%$ of the variance in psychological distress. See Table 6 for a summary of the multiple regression analysis.

Table 6. Forward regression analysis for factors associated with psychological distress (GHQ-12).

\begin{tabular}{ccccc}
\hline & & $\boldsymbol{B}$ & $\boldsymbol{\beta}$ & $\boldsymbol{p}$ \\
\hline Step 1 & Constant & 2.767 & & $<0.001$ \\
& Caregiver burden & 0.442 & 0.579 & $<0.001$ \\
Step 2 & Constant & 4.736 & & $<0.001$ \\
& Caregiver burden & 0.440 & 0.576 & $<0.001$ \\
& Friend or relative to confide in & -2.244 & -0.273 & 0.008 \\
Step 3 & Constant & 4.916 & & $<0.001$ \\
& Caregiver burden & 0.435 & 0.569 & $<0.001$ \\
& Friend or relative to confide in & -1.927 & -0.234 & 0.021 \\
& Help from health workers & -1.204 & -0.209 & 0.039 \\
\hline
\end{tabular}

\section{Discussion}

In the current study, $90.5 \%$ of the caregivers scored above the suggested cutoff $(\geq 2)$ on the GHQ-12. This is much higher than $11.7 \%$ found in the general female population in a rural district of Nepal [49]. Almost half of the caregivers (46\%) scored six or higher, which is the optimum cutoff found by Patel and colleagues to use in very resource-poor settings to best balance between sensitivity and positive predictive value [55]. In contrast, about $10 \%$ of mothers in a large study in a rural district of Nepal scored six or higher [39]. This indicates a higher psychological distress in caregivers of NDD children compared with what was previously reported in the general Nepali rural female population. The finding of a high level of distress in caregivers of NDD children is in line with previous studies of caregivers of children with intellectual disability [33] in Nepal and other studies of children with disabilities in an LMIC setting like India [28], Bangladesh [25], and Sri Lanka [29].

The correlation between child impact on caregiver, the GMFCS score, and psychological distress measured by the GHQ-12 demonstrates that the child's disability seems to put a large overall burden on the caregivers and their families. This is in line with research that has shown that there is a considerable and neglected burden on caregivers in LMIC's in terms of physical, psychological, social, time, and financial burden [3], and that the extra 
care burden related to having a disabled child can have a negative impact also on healthy siblings and marriage [23].

Previous findings have indicated that interventions and preventive strategies targeting caregivers may enable the caregivers to be more responsive to the child's needs, thus decreasing the impact of the child's disability on the caregivers [57], which can improve the wellbeing and the situation of the caregivers [58]. It is reasonable to expect similar results in a low-income setting. It is therefore important to address the situation of the whole family and not just the disabled child. Holistic interventions addressing the total family burden and the caregiver's psychological health therefore seem important.

We found that psychological distress was strongly related to the severity of the child's motor disability as measured by the GMFCS and to perceived caregiver impact. Some of this might be caused by increased workload related to having a severely disabled child. Interventions that can reduce workload may be useful to reduce caregiver's stress. Lack of mobility aids, often combined with inaccessible roads, can be a challenge resulting in both the disabled child and the caregiver becoming housebound. Simple, affordable mobility aids have been used with success in several developing countries [59].

Likewise, feeding problems were associated with psychological distress in the caregiver, and a study from Bangladesh has shown that an intervention to improve the child's feeding skills reduced maternal stress [60].

There was no correlation between the number of help sources and psychological distress. The only help source that was significantly correlated with lower psychological distress was advice and help from health workers, indicating that health workers might have an important role in reducing stress in caregivers. Having a close friend or relative to confide in was also significantly correlated to lower psychological distress as measured by the GHQ-12. This is in line with a review of Ribeiro (2013) that found that social support reduces stress levels in $\mathrm{CP}$ families [61]. Increasing social support might also therefore be important in order to improve the situation of these families. Community-based parent support groups have provided informal peer support as well as help and advice from health personnel $[60,62]$.

Although one could assume that living in an extended family would provide more help for the caregivers, there was no association between psychological distress and family type. This has also been found in studies from Bangladesh [25] and Sri Lanka [29]. The finding of a high stress level in the present study can also be related to a strong feeling of duty towards the family [39], combined with a belief that disability is the result of sinful past actions [63] and the fate of god [40]. In addition, the whole family, but especially mothers of disabled children, is often stigmatized [40]. This might also hamper help-seeking behavior both for the disabled child and for the caregiver.

Having a disabled child can be an economic challenge to the family because the caregiver often becomes housebound and has less possibilities for work outside the home [2,19]. In a setting with little or no governmental support, this may be an even greater problem, leading to increased poverty and debt [20]. The loss of income together with added expenses can have a detrimental effect on caregivers and their families in LMIC [3]. The correlation between disability and poverty is strong: poverty leads to higher rates of disability, and disability increases the risk of poverty [8].

Seventy percent reported that the child's disability had either negative (32\%) or very negative impact $(38 \%)$ on their economy, indicating a substantial economic burden of having a disabled child.

The finding that illiterate caregivers have higher psychological distress is in line with a study from Nigeria that showed that the most important predictors of a caregiver's stress were severity of disability and level of education [64]. Brehaut and colleagues found that caregivers of disabled children had lower academic attainment, limited work opportunities, were more likely to be unemployed, and had lower income levels [17].

The forward regression analysis entering the significant factors from the correlational analysis indicated that caregiver burden, having a friend to confide in, and receiving 
help from health workers predicted psychological distress (GHQ12), after controlling for the effect of the other significant correlations. The factor that explained most of the variance was caregiver burden. This may indicate that measures to decrease caregiver burden are central to reduce psychological distress, as well as providing both informal psychosocial support and professional help. More studies are needed to understand the factors associated with caregiver's psychological distress, as well as how to best introduce measures to reduce psychological distress among NDD caregivers in LMIC countries and in different cultural settings.

\subsection{Strengths and Limitations}

In Nepal, $80 \%$ of the population reside in rural areas. Caregivers living here may have different challenges to caregivers living in a major city. It is therefore a strength that this study was performed in a rural setting and mainly among families who were not already enrolled in a program for NDD. Although case findings, infrastructure, and transportation can be a major challenge, generating knowledge about childhood disability and the caregiver's situation in rural areas in LMIC is important in order to be able to develop better services for this group.

The use of experienced mental health professionals as interviewers and ensuring privacy in the interview setting are strengths of this study. Obtaining valid answers to personal questions, including questions regarding mental health issues, in a context where this is highly stigmatized and little spoken about, requires the interviewers to quickly build rapport and trust with the interviewee and be able to probe further when necessary.

The study has a number of limitations. The sample size is small, and statistical interpretation should be made with caution. Even though the sample was collected from different districts, Nepal is a very ethnically and culturally diverse country and the results may not be representative of the situation for NDD caregivers in rural Nepal. As there is no public register of children with NDD, information about possible children with NDD in the area was gathered from local people, youth clubs, local authorities, and other organizations, and cases might have been missed out. No participants refused to participate in the study. However some families may not have wanted to disclose that they have a disabled child. This may be a bias as such children would not be included in the study.

\subsection{Implications and Recommendations}

The caregiver's situation is often difficult, with a high burden of caregiving severely affecting mental health and quality of life. Lack of services for both disability and mental health seems to be adding to the burden of these caregivers. For most of the caregivers, there seemed to be no available mental health services locally. We suggest that interventions for this group will be more effective if they also involve a specialized and direct focus on caregiver's mental health and coping. Sensitive care and support of the caregivers should be included in the follow-up of disabled children, and the caregivers could be screened with simple tools such as the GHQ-12 for more serious psychological distress. Decreasing caregiver burden and ensuring informal psychosocial support as well as support from health workers may be of importance to reduce psychological distress.

\section{Conclusions}

The study found a high level of psychological distress and high overall burden in caregivers of children with NDD in four districts of Nepal. Perceived caregiver burden was associated with more psychological distress, while having a close friend to confide in and having help from health workers were associated with less psychological distress. More research is needed to understand and address the factor associated with psychological distress in NDD caregivers in the cultural and socioeconomic setting in which the families live their lives. 
Author Contributions: H.K.M., H.M.B., P.M., S.M. and S.D. contributed to the study design. H.K.M., S.M. and P.M. contributed to the data collection. H.K.M., K.H. and E.J. contributed to the statistical analysis. All authors contributed to the interpretation of the data, and drafting of the manuscript, and approved the final version. All authors have read and agreed to the published version of the manuscript.

Funding: Costs related to the data collection in Nepal was funded by the Research Department, Sandviken Hospital, Division of Psychiatry, Haukeland University Hospital. Expenses related to open access publishing where covered by Møre and Romsdal Hospital Trust.

Institutional Review Board Statement: The study was conducted according to the guidelines of the Declaration of Helsinki, and approved by the Nepal Health Research Council and the Regional Committee for Medical and Health Research Ethics (REC West: 2012/2241) in Norway.

Informed Consent Statement: Informed consent was obtained from all subjects involved in the study.

Data Availability Statement: The data presented in this study are available on request from the corresponding author. The data are not publicly available due to privacy restrictions.

Acknowledgments: The study was carried out in cooperation with Multi Agency International Training and Support (UK), represented by Mel Adams, the Centre for Mental Health and Counselling (CMC, Nepal) and the Self-Help Group for Cerebral Palsy (SGCP, Nepal), represented by Bimal Lal Shrestha and Suresh Kaphle. A special thanks to the late Prof. Batuk Prasad Rajbhandari at SGCP for his contribution to the study and for his great effort and heart for NDD children and their caregivers. We are also very grateful to the home visitors from the SGCP working in the districts and to Karuna Kunwar and Baby Nakarmi, the excellent interviewers from the CMC. Additionally, the health team at the United Mission to Nepal, represented by Sushma Rajbansji and Netra Bhatta, are thanked for valuable input into the practical considerations and cultural aspects. Funding was provided by the Research Department at Sandviken Hospital, Health Bergen, for which we are extremely grateful. Special thanks particularly go to Ketil Joachim Ødegaard and Ole Bernt Fasmer at Sandviken for their generous support and help. We would also like to thank all the parents and children involved in the study for their cooperation.

Conflicts of Interest: The authors declare no conflict of interest. The funders had no role in the design of the study; in the collection, analyses, or interpretation of data; in the writing of the manuscript, or in the decision to publish the results.

\section{References}

1. Parkes, J.; Caravale, B.; Marcelli, M.; Franco, F.; Colver, A. Parenting stress and children with cerebral palsy: A European cross-sectional survey. Dev. Med. Child Neurol. 2011, 53, 815-821. [CrossRef] [PubMed]

2. Carnevale, F.A.; Rehm, R.S.; Kirk, S.; McKeever, P. What we know (and do not know) about raising children with complex continuing care needs. J. Child Health Care 2008, 12, 4-6. [CrossRef] [PubMed]

3. Thrush, A.; Hyder, A.A. The neglected burden of caregiving in low- and middle-income countries. Disabil. Health J. 2014, 7 , 262-272. [CrossRef]

4. Rahman, A.; Harrington, R.; Bunn, J. Can maternal depression increase infant risk of illness and growth impairment in developing countries? Child Care Health Dev. 2002, 28, 51-56. [CrossRef]

5. Behrman, R.; Butler, A. Preterm Birth: Causes, Consequences, and Prevention; National Academies Press: Washington, DC, USA, 2007.

6. Bitta, M.; Kariuki, S.; Abubakar, A.; Newton, C. Burden of neurodevelopmental disorders in low and middle-income countries: A systematic review and meta-analysis. Wellcome Open Res. 2018, 2. [CrossRef]

7. UNICEF. The State of the World's Children; 92-806-3817-3; United Nations Children's Fund: New York, NY, USA, 2005.

8. WHO; World Bank. World Report on Disability 2011; World Health Organization: Geneva, Switzerland, 2011.

9. UNICEF. Producing Disability-Inclusive Data: Why it Matters and What it Takes; United Nations Children's Fund: New York, NY, USA, 2020.

10. Durkin, M.S.; Schneider, H.; Pathania, V.S.; Nelson, K.B.; Solarsh, G.C.; Bellows, N.; Scheffler, R.M.; Hofman, K.J. Learning and Developmental Disabilities. In Disease Control Priorities in Developing Countries, 2nd ed.; Jamison, D.T., Breman, J.G., Measham, A.R., Alleyne, G., Claeson, M., Evans, D.B., Jha, P., Mills, A., Musgrove, P., Eds.; Oxford University Press: New York, NY, USA, 2006; pp. 933-951.

11. Newton, C.R. Neurodevelopmental disorders in low- and middle-income countries. Dev. Med. Child Neurol. $2012,54,1072$. [CrossRef]

12. Scherer, N.; Verhey, I.; Kuper, H. Depression and anxiety in parents of children with intellectual and developmental disabilities: A systematic review and meta-analysis. PLoS ONE 2019, 14, e0219888. [CrossRef] 
13. Fritz, H.; Sewell-Roberts, C. Family Stress Associated with Cerebral Palsy. In Cerebral Palsy; Miller, F., Bachrach, S., Lennon, N., O'Neil, M.E., Eds.; Springer International Publishing: Cham, Swiztherland, 2020; pp. 515-545. [CrossRef]

14. Masefield, S.C.; Prady, S.L.; Sheldon, T.A.; Small, N.; Jarvis, S.; Pickett, K.E. The Caregiver Health Effects of Caring for Young Children with Developmental Disabilities: A Meta-analysis. Matern. Child Health J. 2020, 24, 561-574. [CrossRef]

15. Lee, J. Maternal stress, well-being, and impaired sleep in mothers of children with developmental disabilities: A literature review. Res. Dev. Disabil. 2013, 34, 4255-4273. [CrossRef]

16. Barlow, J.H.; Cullen-Powell, L.A.; Cheshire, A. Psychological well-being among mothers of children with cerebral palsy. Early Child Dev. Care 2006, 176, 421-428. [CrossRef]

17. Brehaut, J.C.; Kohen, D.E.; Raina, P.; Walter, S.D.; Russell, D.J.; Swinton, M.; O’Donnell, M.; Rosenbaum, P. The health of primary caregivers of children with cerebral palsy: How does it compare with that of other Canadian caregivers? Pediatrics 2004, 114, e182-e191. [CrossRef]

18. Lee, M.H.; Park, C.; Matthews, A.K.; Hsieh, K. Differences in physical health, and health behaviors between family caregivers of children with and without disabilities. Disabil. Health J. 2017, 10, 565-570. [CrossRef] [PubMed]

19. Stabile, M.; Allin, S. The economic costs of childhood disability. Future Child 2012, 22, 65-96. [CrossRef] [PubMed]

20. Laskar, A.R.; Gupta, V.K.; Kumar, D.; Sharma, N.; Singh, M.M. Psychosocial effect and economic burden on parents of children with locomotor disability. Indian J. Pediatr. 2010, 77, 529-533. [CrossRef] [PubMed]

21. Vadivelan, K.; Sekar, P.; Sruthi, S.S.; Gopichandran, V. Burden of caregivers of children with cerebral palsy: An intersectional analysis of gender, poverty, stigma, and public policy. BMC Public Health 2020, 20, 645. [CrossRef]

22. Thurston, S.; Paul, L.; Loney, P.; Ye, C.; Wong, M.; Browne, G. Associations and costs of parental symptoms of psychiatric distress in a multi-diagnosis group of children with special needs. J. Intellect. Disabil. Res. 2011, 55, 263-280. [CrossRef]

23. Williams, P.; Piamjariyakul, U.; Graff, J.C.; Stanton, A.; Guthrie, A.C.; Hafeman, C.; Williams, A.R. Developmental disabilities: Effects on well siblings. Issues Compr. Pediatr. Nurs. 2010, 33, 39-55. [CrossRef]

24. Majnemer, A.; Shevell, M.; Rosenbaum, P.; Law, M.; Poulin, C. Determinants of life quality in school-age children with cerebral palsy. J. Pediatr. 2007, 151, 470-475, 475 e471-473. [CrossRef]

25. Mobarak, R.; Khan, N.Z.; Munir, S.; Zaman, S.S.; McConachie, H. Predictors of stress in mothers of children with cerebral palsy in Bangladesh. J. Pediatr. Psychol. 2000, 25, 427-433. [CrossRef]

26. McConkey, R.; Truesdale-Kennedy, M.; Chang, M.Y.; Jarrah, S.; Shukri, R. The impact on mothers of bringing up a child with intellectual disabilities: A cross-cultural study. Int. J. Nurs. Stud. 2008, 45, 65-74. [CrossRef]

27. Azar, M.; Badr, L.K. The adaptation of mothers of children with intellectual disability in Lebanon. J. Transcult. Nurs. 2006, 17, 375-380. [CrossRef]

28. Shanbhag, D.; Krishanmurthy, A. Mental Health and Quality of Life of Caregivers of Individuals with Cerebral Palsy in a Community Based Rehabilitation Programme in Rural Karnataka. Disabil. CBR Incl. Dev. 2012, 22, 29-38. [CrossRef]

29. Wijesinghe. Prevalence and predictors of psychological problems among principal caregivers of children with cerebral palsy in Galle, Sri Lanka. J. Coll. Community Phys. Sri Lanka 2014, 19, 8-17. [CrossRef]

30. Sharma, S.; Mehra, S. Prioritizing the needs of young people with disabilities in low- and middle-income countries: An evidence-based summary. J. Family Med. Prim. Care 2020, 9, 470-472. [CrossRef]

31. Sharma, R.; Sharma, S.C.; Pradhan, S.N. Assessing Caregiver Burden in Caregivers of Patients with Schizophrenia and Bipolar Affective Disorder in Kathmandu Medical College. J. Nepal Health Res. Counc. 2018, 15, 258-263. [CrossRef]

32. Mishra, S.K.; Pandey, A.K.; Adhikari, B.R.; Nepal, S. Caregiver burden and coping strategies in schizophrenia: A hospital based study. J. Psychiatr. Assoc. Nepal 2017, 5, 26. [CrossRef]

33. Sapkota, N.; Pandey, A.K.; Deo, B.K.; Shrivastava, M.K. Anxiety, depression and quality of life in mothers of intellectually disabled children. J. Psychiatr. Assoc. Nepal 2017, 6. [CrossRef]

34. CIA. Nepal. Available online: https://www.cia.gov/library/publications/the-world-factbook/geos/np.html (accessed on 8 February 2021).

35. Wright, C.; Nepal, M.K.; Bruce-Jones, W.D. Mental health patients in primary health care services in Nepal. Asia Pac. J. Public Health 1989, 3, 224-230. [CrossRef] [PubMed]

36. Simpson, P.L.; Schumaker, J.F.; Dorahy, M.J.; Shrestha, S.N. Depression and life satisfaction in Nepal and Australia. J. Soc. Psychol. 1996, 136, 783-790. [CrossRef] [PubMed]

37. Knight, B.; Sayegh, P. Cultural Values and Caregiving: The Updated Sociocultural Stress and Coping Model. J. Gerontol. 2009, 65B, 5-13. [CrossRef]

38. Westbrook, M.T.; Legge, V.; Pennay, M. Attitudes towards disabilities in a multicultural society. Soc. Sci. Med. 1993, 36, 615-623. [CrossRef]

39. Clarke, K.; Saville, N.; Shrestha, B.; Costello, A.; King, M.; Manandhar, D.; Osrin, D.; Prost, A. Predictors of psychological distress among postnatal mothers in rural Nepal: A cross-sectional community-based study. J. Affect. Disord. 2014, 156, 76-86. [CrossRef]

40. Human Rights Watch. Futures Stolen: Barriers to Education for Children with Disabilities in Nepal; Human Rights Watch: New York, NY, USA, 2011.

41. Regmi, S.K.; Pokharel, A.; Ojha, S.P.; Pradhan, S.N.; Chapagain, G. Nepal mental health country profile. Int. Rev. Psychiatry 2004, 16, 142-149. [CrossRef] 
42. Jha, A.; Adhikari, S.R. Mental health services in New Nepal—Observations, objections and outlooks for the future. J. Nepal Med. Assoc. 2009, 48, 185-190. [CrossRef]

43. Luitel, N.P.; Jordans, M.J.D.; Kohrt, B.A.; Rathod, S.D.; Komproe, I.H. Treatment gap and barriers for mental health care: A cross-sectional community survey in Nepal. PLoS ONE 2017, 12, e0183223. [CrossRef]

44. American Psychiatric Association. Diagnostic and Statistical Manual of Mental Disorders, 4th ed.; American Psychiatric Association: Washington, DC, USA, 2000.

45. Durkin, M.S.; Wang, W.; Shrout, P.E.; Zaman, S.S.; Hasan, Z.M.; Desai, P.; Davidson, L.L. Evaluating a ten questions screen for childhood disability: Reliability and internal structure in different cultures. J. Clin. Epidemiol. 1995, 48, 657-666. [CrossRef]

46. Wu, L.; Katz, J.; Mullany, L.C.; Khatry, S.; Darmstadt, G.; LeClerq, S.C.; Tielsch, J.M. The association of preterm birth and small birthweight for gestational age on childhood disability screening using the Ten Questions Plus tool in rural Sarlahi district, southern Nepal. Child Care Health Dev. 2012, 38, 332-340. [CrossRef]

47. Palisano, R.J.; Rosenbaum, P.; Bartlett, D.; Livingston, M.H. Content validity of the expanded and revised Gross Motor Function Classification System. Dev. Med. Child Neurol. 2008, 50, 744-750. [CrossRef]

48. Palisano, R.J.; Rosenbaum, P.; Walter, S.; Russell, D.; Wood, E.; Galuppi, B. Development and reliability of a system to classify gross motor function in children with cerebral palsy. Dev. Med. Child Neurol. 1997, 39, 214-223. [CrossRef]

49. Koirala, N.R.; Regmi, S.K.; Sharma, V.D.; Khalid, A.; Nepal, M. Sensitivity and validity of the General Health Questionnaire (GHQ-12) in a rural community setting in Nepal. Nepal. J. Psychiatry 1999, 1, 34-40.

50. Fernandes, A.C.; Hayes, R.D.; Patel, V. Abuse and other correlates of common mental disorders in youth: A cross-sectional study in Goa, India. Soc. Psychiatry Psychiatr. Epidemiol. 2013, 48, 515-523. [CrossRef]

51. Hayes, S.A.; Watson, S.L. The Impact of Parenting Stress: A Meta-analysis of Studies Comparing the Experience of Parenting Stress in Parents of Children With and Without Autism Spectrum Disorder. J. Autism Dev. Disord. 2012, 43, 629-642. [CrossRef]

52. Patel, V.; Ramasundarahettige, C.; Vijayakumar, L.; Thakur, J.S.; Gajalakshmi, V.; Gururaj, G.; Suraweera, W.; Jha, P.; Million Death Study Collaborators. Suicide mortality in India: A nationally representative survey. Lancet 2012, 379, 2343-2351. [CrossRef]

53. Werneke, U.; Goldberg, D.P.; Yalcin, I.; Ustün, B.T. The stability of the factor structure of the General Health Questionnaire. Psychol. Med. 2000, 30, 823-829. [CrossRef] [PubMed]

54. Cuéllar-Flores, I.; Sánchez-López, M.P.; Limiñana-Gras, R.M.; Colodro-Conde, L. The GHQ-12 for the assessment of psychological distress of family caregivers. Behav. Med. 2014, 40, 65-70. [CrossRef]

55. Patel, V.; Araya, R.; Chowdhary, N.; King, M.; Kirkwood, B.; Nayak, S.; Simon, G.; Weiss, H.A. Detecting common mental disorders in primary care in India: A comparison of five screening questionnaires. Psychol. Med. 2008, 38, 221-228. [CrossRef] [PubMed]

56. Goldberg, D.; Williams, P. A User's Guide to the General Health Questionnaire; NFER-NELSON: Windsor, UK, 1988.

57. Raina, P.; O'Donnell, M.; Rosenbaum, P.; Brehaut, J.; Walter, S.D.; Russell, D.; Swinton, M.; Zhu, B.; Wood, E. The health and well-being of caregivers of children with cerebral palsy. Pediatrics 2005, 115, e626-e636. [CrossRef] [PubMed]

58. Irwin, L.; Jesmont, C.; Basu, A. A systematic review and meta-analysis of the effectiveness of interventions to improve psychological wellbeing in the parents of children with cerebral palsy. Res. Dev. Disabil. 2019, 95, 103511. [CrossRef] [PubMed]

59. Werner, D. Disabled Village Children: A Guide for Community Health Workers, Rehabilitation Workers, and Families; Hesperian Health Guides: Berkeley, CA, USA, 1987.

60. Adams, M.S.; Khan, N.Z.; Begum, S.A.; Wirz, S.L.; Hesketh, T.; Pring, T.R. Feeding difficulties in children with cerebral palsy: Low-cost caregiver training in Dhaka, Bangladesh. Child Care Health Dev. 2012, 38, 878-888. [CrossRef] [PubMed]

61. Ribeiro, M.F.; Porto, C.C.; Vandenberghe, L. Parental stress in families of children with cerebral palsy: An integrative review. Cien Saude Colet 2013, 18, 1705-1715. [CrossRef]

62. Zuurmond, M.; Nyante, G.; Baltussen, M.; Seeley, J.; Abanga, J.; Shakespeare, T.; Collumbien, M.; Bernays, S. A support programme for caregivers of children with disabilities in Ghana: Understanding the impact on the wellbeing of caregivers. Child Care Health Dev. 2018, 45. [CrossRef] [PubMed]

63. Thapaliya, M. A Report on Disability in Nepal; Australian Himalayan Foundation: Sydney, Australia, 2016.

64. Omole, J.; Adegoke, S.; Omole, K.; Mbada, C.; Adedeji, G.; Adeyemi, O. Levels, Correlates, and Predictors of Stress and Caregiver Burden among Caregivers of Children with Cerebral Palsy in Nigeria. J. Pediatr. Neurol. 2019, 17, 13-21. [CrossRef] 